\title{
Reading for Integration, Identifying Complementary Threshold Concepts: The ACRL Framework in Conversation with Naming What We Know: Threshold Concepts of Writing Studies
}

Brittney Johnson

St. Edward's University, bjohnso1@stedwards.edu

I. Moriah McCracken

St.Edward's University, ilamc@stedwards.edu

Follow this and additional works at: https://pdxscholar.library.pdx.edu/comminfolit Let us know how access to this document benefits you.

\section{Recommended Citation}

Johnson, B., \& McCracken, I. (2016). Reading for Integration, Identifying Complementary Threshold Concepts: The ACRL Framework in Conversation with Naming What We Know: Threshold Concepts of Writing Studies. Communications in Information Literacy, 10 (2), 178-198. https://doi.org/10.15760/ comminfolit.2016.10.2.23

This open access Research Article is distributed under the terms of the Creative Commons AttributionNonCommercial-ShareAlike 4.0 International License (CC BY-NC-SA 4.0). All documents in PDXScholar should meet accessibility standards. If we can make this document more accessible to you, contact our team. 


\section{Reading for Integration, Identifying Complementary Threshold Concepts: The ACRL Framework in Conversation with Naming What We Know: Threshold Concepts of Writing Studies

\author{
Brittney Johnson, St. Edward's University \\ I. Moriah McCracken, St. Edward's University
}

Abstract

In 2015, threshold concepts formed the foundation of two disciplinary documents: the $A C R L$ Framework for Information Literacy (2015) and Naming What We Know: Threshold Concepts of Writing Studies (2015). While there is no consensus in the fields about the value of threshold concepts in teaching, reading the six Frames in the ACRL document alongside the threshold concepts of writing studies illuminates overlapping elements that may empower faculty in both fields to advocate collectively against skills-focused writing and research instruction through cross-disciplinary integrations. To facilitate cross-disciplinary conversations around the documents, the authors propose an order for reading the Frames, identify the associated writing concepts, and explain how the shared concepts reveal an internal complexity which may have implications for teaching the ACRL Framework.

Keywords: threshold concepts; information literacy; writing studies; ACRL Framework; Naming What We Know

Johnson, B. \& McCracken, I.M. Reading for integration, identifying complementary threshold concepts: The ACRL Framework in conversation with Naming what we know: Threshold concepts of writing studies. Communications in Information Literacy, 10(2), 176-197.

Copyright for articles published in Communications in Information Literacy is retained by the author(s). Author(s) also extend to Communications in Information Literacy the right to redistribute this article via other scholarly resources and bibliographic databases. This extension allows the authors' copyrighted content to be included in some databases that are distributed and maintained by for-profit companies. All other rights of redistribution are licensed by Communications in Information Literacy under Creative Commons Attribution-NonCommercial-ShareAlike 4.0 International (CC BYNC-SA 4.0). 


\section{Reading for Integration, Identifying Complementary Threshold Concepts: The ACRL Framework in Conversation with Naming What We Know: Threshold Concepts of Writing Studies}

Information literacy programs and first-year writing programs have a documented history of coordination, and professionals in these two distinct but inter-related fields have formed complex collaborations, as Reid's (2014) research bibliography on partnerships between first-year writing programs and university libraries made clear. Reid provided scholars in writing studies with a comprehensive overview of this ongoing "coordination," but even as she was exploring the published research on the practical and theoretical connections between these distinct disciplines, there were separate but concurrent efforts by teachers and researchers in writing studies and information literacy to investigate the role threshold concepts could play in revitalizing how instructors teach writing and information literacy.

In the spring of 2015, the Association of College and Research Libraries (ACRL) filed its new Framework for Information Literacy for Higher Education (Framework), articulating the role of threshold concepts in information literacy. In July 2015, Naming What We Know: Threshold Concepts of Writing Studies (NWWK) was published. Both documents are grounded in threshold concepts, which, as explained by Meyer and Land (2003) are most often described as disciplinary portals or gateways because they represent "a transformed way of understanding, or interpreting, or viewing something without which the learner cannot progress" (p. 1). That is, these discipline-specific concepts are responsible for "opening up a new and previously inaccessible way of thinking about something" (p. 1).

Meyer and Land's description of threshold concepts reads, initially, as a simple rearticulation of what many academics already know: disciplines have ways of seeing and "ways of thinking" (p. 10). What is significant about Meyer and Land's threshold concepts, we suggest, is how scholars and researchers in writing studies and information literacy can use this shared vocabulary and conceptual framework to collaborate on and revise existing curricula. Threshold concepts create theoretical space for scholars, instructors, and librarians to explore the goals and aims of their respective disciplines. 
The value of threshold concepts within information literacy and writing studies is not yet settled, nor are the threshold concepts themselves. Public debate and conversation is essential for naming a discipline's way of thinking, but as the recent special section "First Thoughts on the Framework" (2015) in Communications in Information Literacy suggested, there are good reasons for moving forward with our exploration of their pedagogical value. For instance, threshold concepts call on us to focus on how students are understanding and progressing through disciplinary content. Jacobson and Gibson (2015) suggested that " $[\mathrm{t}]$ he Framework affords a broader, integrated set of 'big ideas' about research, scholarship, and information" (p. 104), and we agree. The shared interest in threshold concepts across our fields means that writing programs and information literacy programs must (at the very least) reconsider what effective information literacy instruction means. In particular, a point raised by Pagowsky (2015) resonates with our work here. Pagowsky claimed that even tentative agreement on particular threshold concepts may "[...] shape how we could teach rather than being stuck on how we are expected to teach" (p. 141, original emphasis). For new integrations and partnerships to work, library and writing program instructors and administrators need to examine the ACRL Framework for Information Literacy in Higher Education (2015) and Naming What We Know: Threshold Concepts of Writing Studies (2015) in order to identify shared conversations and complementary elements. We must use the publication of these documents as a kairotic moment-as an opportunity for rich, crossdisciplinary integration that could potentially empower teachers in two separate fields to advocate collectively against one-off, skills-focused writing and research instruction. The purpose of this paper is to expedite library and writing program collaborations by outlining one way to identify the complementary-or shared-threshold concepts of information literacy and writing studies.

\section{Method}

\section{Structural Considerations}

In "This is Really Happening," Seeber (2015) acknowledged the various debates surrounding the Framework, but he also put those debates aside to create a "pedagogical document," which included a reading of the document's six Frames to "investigate how the notion of context is discussed within each one" (p. 159). This article focuses on threshold concepts, and like Seeber, our goal is pedagogical in nature. We want to illustrate the shared-and we'll argue complementary-concepts articulated in two separate publications so that other 
programs might consider how these concepts might inform the pedagogical objectives and goals of library instruction and first-year writing programs.

In the Framework, the threshold concepts of information literacy are organized as six Frames of interconnected, core concepts. Each Frame includes a definition and description of the core threshold concept, followed by an outline of specific knowledge practices and dispositions that are indicators of what learners will experience as they move from novice to expert within the context of that Frame and information literacy in general. NWWK was assembled by co-editors, not a national organization, and the editors invited 45 teacherscholars to contribute 500-1000 word definitions in a crowd-sourced wiki discussion. The end product includes one meta-concept for writing studies followed by 37 encyclopediastyle entries for writing-specific threshold concepts. These 37 concepts are grouped into five categories, which make up Part I of the edited collection. Part II focuses on in-depth explorations for the use of threshold concepts across eight sites of writing instruction, including first-year writing courses.

The Framework presents "a cluster of interconnected core concepts" (ACRL, 2015) which are organized alphabetically. In contrast, the concepts included in NWWK are presented with numbers for the five categories; however, this numbering system does not imply a set order nor does the numbering system indicate a definitive list. As the editors make clear:

The concepts and definitions here represent what we know for now; their existence as knowing concepts is currently critical for epistemological participation in [writing studies] disciplines, and many of them are, we think, critical for anyone who wants to help learners write more effectively, whatever their disciplines or professions may be. That this knowledge will continue to change, and that what we see as most important will continue to evolve, is inevitable and desirable if we are to continue to grow as a field. (p. 5)

The Framework and NWWK identify the current threshold concepts driving each field, but there are no clear one-to-one connections between descriptions and definitions. One document has clear definitions; the other offers short encyclopedic entries about a named concept. It is empowering for instructors that neither set of concepts comes with a pre-set order or even firm recommendations about sequencing. This lack of ranking means that programs and instructors must unpack the concepts and implement them in ways that best fit institutional missions and student needs. For programs to build cross-campus 
partnerships around these documents, we argue that they must first determine which pedagogically-related overlaps make sense in their local contexts. The local context is essential because the content presented by each field is substantively distinct and because neither gives priority or preference to any particular concept. Below we share how we approached the challenge of reading both documents to extract explicitly the overlapping threshold concepts of information literacy and writing studies.

\section{Procedure}

We began our shared knowledge-making exercise by comparing the concepts outlined in each document. Because we were trying to make meaning of foundational texts, we focused on making content-based comparisons to identify overlapping ideas. We used the definitions and descriptions of the six ACRL Frames to ground the more abstract (and less settled) writing studies concepts. As we read the sections of $N W W K$, we each identified quotes from the chapters that echoed ideas from the six Frames. Then, for each threshold concept from each discipline, we noted (1) key features of the concept itself, (2) connections to our existing programs, and (3) comments about future collaborations or implications. Thus, each concept was read in light of our existing program goals and assignments with particular attention paid to how each concept intersected with disciplinary values. We were not yet focused on teaching, so outcomes and assessments are not discussed here.

We have organized our discussion into six sections, corresponding to the six Frames presented by the Framework. Each section offers an overview of the Frame, working from the Framework's definition and description. We elected not to use each Frame's knowledge practices or dispositions for this project because the writing studies threshold concepts do not touch on assessment of student learning; instead, $N W W K$ entries articulate why each concept might be troublesome for students. Comparing assessment- and/or outcomefocused information did not seem beneficial for programs, like ours, which are exploring new threshold concept-focused collaborations. After presenting our reading of each Frame, we discussed the shared threshold concepts from writing studies, using the corresponding threshold concept numbers included in Part I of NWWK. This organization should clarify the comparison identified and the corresponding threshold concepts under review.

\section{Results}

We begin our discussion below by proposing an alternative to the alphabetic presentation of the six Frames. The discussion offered below is not a definitive comparison of shared 
concepts nor does it include specific recommendations related to pedagogical design; however, the relationships we have identified here may expedite the work of information literacy programs at other institutions seeking new partnerships with various writing courses and programs. We hope to illustrate how identifying a driver for the other Frames can, in fact, help scaffold a redesign for the collaborative teaching of our fields' interrelated threshold concepts.

Scholarship as Conversation

As defined in the Framework, Scholarship as Conversation embodies the "sustained discourse" that "communities of scholars, researchers, or professionals engage in [...] over time as a result of varied perspectives and interpretations" (ACRL, 2015). One direct overlap between the Framework and NWWK centers on the Frame's description of research as a "discursive practice in which ideas are formulated, debated, and weighed against one another over extended periods of time" (ACRL, 2015).

Two concepts from NWWK explicitly discuss the idea of conversations happening over time-what writing scholars often refer to as the "situatedness of writing"-and further illustrate the ongoing nature of communicating, learning, and building from one another in the context of scholarship. The situatedness of writing is first explored in the concept Writing is a Social and Rhetorical Activity (1.0). Roozen (2015) argued that writing is always "an attempt to respond adequately to the needs of an audience," and because this discursive practice requires an audience, "writing can never be anything but a social and rhetorical act, connecting us to other people across time and space" (p. 18). Roozen stressed that writing enables writers to make meaning with the audience through making connections and agreements. That meaning-making is a communal process-one that occurs when author and audience work together to explore ideas and engage in discussion over time-is reflected in the description of Scholarship as Conversation: "a given issue may be characterized by several competing perspectives as part of an ongoing conversation in which information users and creators come together and negotiate meaning" (ACRL, 2015). Four more concepts from writing studies further explore this idea of scholars negotiating meaning throughout the evolution of the conversation. Estrem (2015) described the epistemological nature of writing as a "mulling over a problem, thinking with others, and exploring new ideas or bringing disparate ideas together" (p. 19) in her discussion of how Writing is a Knowledge-Making Activity (1.1). Lunsford (2015) also considers how writers 
think with, and for, others by focusing on the co-creation of meaning as related to audiences. In Writing Addresses, Invokes, and/or Creates Audiences (1.2), Lunsford described writing as "both relational and responsive, always in some way part of an ongoing conversation with others" (p. 20). In both concepts, Estrem and Lunsford argued that writing is the means by which scholars can participate in the conversation to either create new knowledge or engage with readers. Both noted that through writing, scholars are not simply talking at one another about their research; instead, scholars engaged in conversations are actually thinking with one another about their research.

Two additional writing studies concepts explore meaning-making in conversation at a more granular level. Roozen (2015) captured the conversational nature of scholars "talking" to one another when exploring how Texts Get Their Meaning from Other Texts (2.6). Like the Framework, this concept highlights the key role published discourse plays in conversations. Roozen notes the conversation happening in texts when he said that "texts always refer to other texts [emphasis added] and rely heavily on those texts to make meaning" (p. 44); in this way, "texts are profoundly intertextual in that they draw meaning from a network of other texts" (p. 44). Scholars work from theoretical and conceptual ideas embedded in longer projects, but they also work from smaller, discursive units, an issue raised by Dryer (2015), who narrowed Roozen's focus by arguing that scholarly conversations often make meaning because Words Get Their Meanings from Other Words (1.4). This micro consideration pertains to the Scholarship as Conversation Frame because Dryer claims that writers must understand that meaning is influenced by "language users' context and motives" and that writers and scholars "can reduce the likelihood of misunderstandings" through "careful framing” (p. 25). Dryer called attention to how scholars use and represent other conversations-and words-in their own works. While Dryer did not refer to the broader network of scholars negotiating meaning at the word level, there is an underlying practice that he did investigate: meaning is determined, in large part, through the dance between reader and writer-the negotiation that occurs when the writer considers the reader's context, experiences, and motives and frames the writing in a way that is responsive to that understanding. This reader-writer exchange, which happens on and off the page, directly pertains to the negotiation of meaning that occurs in the ongoing conversation between scholars and their audiences.

As the above concepts embedded in both the Framework and NWWK make clear, students must understand the ways in which scholarship occurs as conversation in order to 
participate fully in research-based writing in higher education. Students need to understand what it looks like when scholars negotiate the meaning and implications of an idea over time. This means students must also consider the larger structures inherent in those situated conversations. As novices, students need to develop "familiarity with the source's evidence, methods, and modes of discourse in the field" (ACRL, 2015) in order to enter successfully, and eventually contribute to, the conversation.

In NWWK, Bazerman (2015) explores modes of discourse by focusing on the genres, or forms, of writing in his discussion for how Writing Speaks to Situations through Recognizable Forms (2.0). Bazerman focused on the situatedness of scholars, particularly a community of scholars in a discipline, illustrating how writing "addresses social situations and audience $[. .$.$] through recognizable forms associated with those situations and social$ groups" (p. 35). Bazerman-and other writing studies scholars-focused on the individual creating the text, not just the product. He elaborated further, suggesting that "to engage in a disciplinary discussion [...], we need to know how each text is entering into a debate or accumulating past findings or projecting future plans" (p. 36). Familiarity with "modes of discourse in the field," as the ACRL describes, is extended here in the writing studies' threshold concepts. Together, both documents demonstrate that students must understand both the language of a discipline or field and the methods used by those scholars to engage in conversation. Students need to know how scholars are talking, which involves understanding the genres and what counts as evidence and meaning-making (or the accepted methodologies). Understanding how scholars engage in conversations, therefore, becomes an iterative process as students move away from a novice understanding and toward more expert representations of disciplinary conversations and research.

For students to participate in increasingly complex conversations across their academic careers, instructors need to replicate the recursive and iterative process of conversations. Instructors need to design pedagogical experiences that allow students to work in a variety of disciplines and across communities because, as writing studies concepts remind instructors, students need to understand that Learning to Write Effectively Requires Different Kinds of Practice, Time, and Effort (4.3). Yancey (2015) recognized that this particular concept would be troublesome for (most) students. There is a misconception that good writers are naturally good at writing; therefore, many students (and instructors) believe that writing well in one form or genre means a writer will be successful with others. This concept is also troublesome because it argues that effective writing requires practice 
with writing-practice that must be situated within communities and embedded within conversations. As Yancey argued, "[T]his threshold concept locates writing specifically as a practice situated within communities, which suggests how complex writing is and how, as an activity, it spans a lifetime" (p. 65). Understanding Scholarship as Conversation means helping students understand that this concept is not one easily settled; instead, as students enter new communities, disciplines, and careers, they will need to re-engage in this process of time, practice, and effort to understand how perspectives and information are exchanged. They will need to revisit the situatedness of conversations and reconsider how their work engages with existing and ongoing research.

When considering the threshold concept of Scholarship as Conversation and the various overlapping threshold concepts of writing studies, it may help programs to view this Frame as the driver, taking information consumers along the path toward eventual contribution to a scholarly conversation. We suggest that meaningful pedagogical practice begins with a reordering of the Frames, beginning with this one. In the context of teaching, if students see this concept as the driver, they are better positioned to understand the complexities of entering a conversation that is (and has been) ongoing; furthermore, approaching Scholarship as Conversation as the driving threshold concept in information literacy enables educators to introduce the remaining five threshold concepts at critical moments when they naturally fit within the context of the scholarly conversation that students are investigating. Research as Inquiry

If Scholarship as Conversation is the driving threshold concept of information literacy, Research as Inquiry serves as its underlying foundation-the Frame that can best situate the exploration of ideas and conversations in a field. The Framework defines Research as Inquiry as "asking increasingly complex or new questions" to investigate "problems or questions in a discipline or between disciplines that are open or unresolved" in a collaborative effort to "extend the knowledge in that [discipline]" (ACRL, 2015). In essence, research is the process in which the conversation-the inquiry-is situated.

This process of asking questions, investigating, and exploring ideas is reflected in writing studies concepts. Bazerman (2015), as discussed above, was interested in the recognizable forms writing takes (2.0). In addressing the exploratory nature of research and writing, he discussed the inherent unknowns of the situation: "[W]ith writing we have fewer here-andnow clues about what the situation is, who our audiences are, and how we want to respond" 
(p. 35). The unknowns of the writing process are directly related to the unknowns inherent in research because this incomplete understanding of a situation can serve as the point of entry for exploring the problems, questions, or gaps in the conversation that are open or unresolved. This is why research-based writing can be a way of making knowledge and contributing to a discipline.

As discussed above, Estrem (2015) described writing as a mulling, thinking, exploring process; but she also emphasized how " $[\mathrm{u}]$ nderstanding the knowledge-making potential of writing can help people engage more purposefully with writing for varying purposes" (p. 20). Helping students understand research as inquiry, not as reporting on sources as a means of "satisficing" an instructor (Warwick, Rimmer, Blandford, Gow \& Buchanan, 2009) should be a key outcome of our programs. Inquiry as the motivation for research-based writing means asking students to perform as disciplinary contributors, but this can only happen if they, as Lunsford (2015) described in Writing Is Performative (2.5), see writing as having the "capacity to actually produce thought and knowledge" (p. 44). Students engaging in inquiry-based research projects designed to help them understand scholarship as a conversation are more likely to give "rise to new ideas, new insights into [a] topic" (p. 44) because they will be participating in writing as a process, not an answer-finding exercise. The connection here-exploring a problem and letting ideas give rise to new ideas-speaks directly to research as inquiry; moreover, the overlap lies in the processes of writing and research as exploratory investigations into unresolved or interesting problems and ideas.

\section{Authority is Constructed and Contextual}

The Framework describes authority as "a type of influence recognized or exerted within a community" (ACRL, 2015). Determining the level of authority necessary for a particular writing and research-based task means students need to exercise both "informed skepticism and an openness to new perspectives, additional voices, and changes in schools of thought" (ACRL, 2015). Not only should they be prepared to “critically examine all evidence," but students also must be able to "ask relevant questions about origins, context, and suitability of the current information need" (ACRL, 2015). We suggest that helping students understand the information they need begins with helping them understand the more abstract notion of authority as constructed. If instructors first help students understand how the act of writing is situated in a variety of complex ways, then students may be better prepared to understand the construction and limitations on authority. The first category of concepts in NWWK, 
especially Writing is A Social and Rhetorical Activity (1.0), addressed how authority is both constructed and contextual. We discussed 1.0 above, highlighting its emphasis on how writing connects across space and time. Here we focus on the more abstract aspect of situatedness, which grounds the production of written texts.

Too often students and instructors characterize writing as a product and not an activity. Too often the "shorthand descriptions we use to talk and think about writing" (Roozen, 2015, p. 18) drive our conversations. For example, students tell us they write emails and send text messages, but, as Roozen noted, this focus on products obscures the fact that writers send those emails and text messages to audiences for a reason-with an intended purpose. The purpose behind the act of writing is key for understanding the contextual nature of authority because writing is not autonomous (p. 18). By sending purposeful messages to an intended audience, "writers are always connected to other people” (p. 17). And because the act of writing is about connecting individuals, writing is, as discussed above, "always an attempt to address the needs of an audience" (Roozen, p. 17). The needs of an audience, what writing scholars refer to as the purpose or exigence of a written product, therefore, motivates the act of writing; thus, "writing can never be anything but a social and rhetorical act" (p. 18). Students who understand this social and rhetorical nature of writing will be better positioned to see themselves as authors-as individuals with authority to connect with others across time and space. Students who understand the writing they produce as situated are, thus, better positioned to understand how the authority of authors and experts is also contextual and rhetorical.

Understanding authority as constructed and contextual challenges students to do more than report on sources they have determined to be authoritative in a particular context. Students who are expected to see their own words in conversation with the scholarship of the discipline are being asked to focus on how words get their meaning from other words (1.4); they are being asked to understand "that meanings are not determined by history or Webster's prescriptions alone, but also by language users' contexts and motives" (Dryer, 2015, p. 25). Students who can "understand that the definitions of any word develop from its usage" are students who can also "realize that they, too, are part of this process; every instance of their language use works to preserve certain meanings and to advance others" (Dryer, 2015, p. 25). By paying attention to how key terms and concepts evolve in disciplinary conversations, students begin to see how types of authority impact the words being used. By encouraging students to think about their language use and construction of 
audience, instructors prepare students to consider how scholarship is used across disciplines; instead of seeking objective or unbiased texts, students can come to see "that writing expresses and shares meaning to be reconstructed by the reader" (Bazerman, 2015, p. 22).

This concept, Writing Expresses and Shares Meaning to be Reconstructed by the Reader (1.3), may be especially troubling for students "because there is a tension between the expression of meaning and the sharing of it" (p. 22). Students will expect writing to be the clear transmission of information, rather than the dissemination of disciplinary claims. Writing scholars often refer to this evolutionary development as the physics of writing-the situation of ideas and concepts across both time and space-but in the context of shared threshold concepts, instructors can help students understand ecosystems of knowledge and authority by, again, emphasizing how disciplines use writing to make knowledge (1.1). When students are asked to think of their own authority as constructed and contextual even as they consider the knowledge they want to contribute back to a specific discipline, instructors are helping students think about what writing can do for them as they-the novice undergraduate scholars-mull, contribute, and write back. These shared concepts help instructors explain why entering the conversation is about thinking with others and not merely talking at them or about their research. After all, as Estrem argued, academics and scholars-both expert and novice-“write to think” (p. 19, original emphasis). If instructors can draw student attention to the choices an individual writer makes, students may better understand the impact a source's credibility has on community standards and practices, which may increase a student's acceptance of different types of authority (ACRL, 2015).

Understanding that all acts of writing are about sending a message to someone for some reason is an essential step in preparing students to see the context of their messages. Above, we discussed that writing actually creates audiences (1.2), and this concept complements the contextual nature of information needs by helping students understand the rhetorical nature of writing. Talking about the relational and responsive nature of writing in the context of audience helps students remember that they are contributing to conversations, and each new conversation that they enter will require new considerations of what counts as authority in that new community. To respond to the needs of an audience means responding to expectations of authority on the topic under discussion. This emphasis on response can help students "determine the level of authority required" (ACRL, 2015), which is a key component of creating information. 


\section{Information Creation as a Process}

The Framework makes clear that information creation is a process, in part, because "information in any format is produced to convey a message and is shared via a selected delivery method" (ACRL, 2015). The emphasis in writing studies will not be on format or mode of delivery but on genre. Hart-Davidson (2015) noted in Genres Are Enacted by Writers and Readers (2.2) that writing studies scholars understand genre as more than "a form of discourse recognizable as a common set of structural or thematic qualities" (p. 39). Instead of focusing on format or mode of delivery, writing studies scholars emphasize that genres are grounded in "the visible effects of human action, routinized to the point of habit in specific cultural conditions" (p. 39, original emphasis). Novices new to a discipline may mistakenly think of genres as simply "[r] egularities of textual form” (p. 39). But to truly understand the information creation process, students need to understand genres as "repeated instances of action," actions that "are reinforced by institutional power structures" (Hart-Davidson, 2015, pp. 39-40).

The emphasis on action may make the complementary concepts of genre and information creation troublesome for students. As discussed above, written products are disseminated in the genres associated with particular situations and social groups (Bazerman, 2015). Genres can, therefore, help students "recognize the kinds of messages a document may contain" even as these same genres help students "understand how documents move from among and between spaces" (Bazerman, 2015, p. 36). When connected to Scholarship as Conversation, this concept helps students enter conversations because they are "[d]eveloping familiarity with the sources of evidence, methods, and modes of discourse in the field” (ACRL, 2015). But, as the Framework recognizes, engaging with the genre (or mode of discourse) is about looking "to the underlying processes of creation as well as the final product to critically evaluate the usefulness of the information" (ACRL, 2015). For experts, the traces of the creation process may be understood, even if they are no longer visible. Students, in contrast, may not know to look for this evidence. As Bazerman explained, students may struggle to see the complexity of genres, and by extension the complexity of the information creation process, because published final products may provide fewer "clues" for novice readers (p. 35). The original impetus for the creation of information, including the original purpose, may be lost for novices. Students will, therefore, need help in recognizing how the choices of the final product-the source's format, for example-are connected to an ongoing, iterative production process. Students must be taught how to read for the residue of the 
information creation process, and this may best be accomplished through disciplinary investigations. In Writing as a Way of Enacting Disciplinarity (2.3), Lerner (2015) emphasized how genres help students recognize how "[d]ifferent formats also convey different disciplinary values" (p. 41). Understanding the underlying (and perceived) values embedded within those genres-the decisions made to produce information in a particular format-can impact how students as researchers, readers, and consumers interact with and engage with various information types. In working with various genres across disciplines, students can begin to see how "any disciplinary genre speaks to the processes by which members of a discipline shape, make distinct, and value its forms and practices of knowledge creation and communication" even as these same students come to understand how "these processes, in turn, are shaped by the histories of those genres" (p. 41).

This Frame emphasizes the genres, or forms, of the messages as well as the "iterative processes of researching, creating, revising, and disseminating," which will vary depending on the information to be communicated (ACRL, 2015). The writing concept that Assessment is an Essential Component of Learning to Write (4.5) tackles the role of external assessment in shaping written products. O'Neill (2015) explained how assessment, particularly in a classroom, can help instructors focus student attention on the process of communicating information: "[t]hrough the prewriting, drafting, revision, editing, and publishing of a text, writers assess various components of the rhetorical situation as well as a variety of texts" (pp. 67-68). As both producers and consumers of information, students shift from interpreting and understanding messages sent (as readers) to analyzing the content of a message and its intended meaning (as writers). Students are making decisions throughout this process. Most importantly, they are selecting "the appropriate genre, writing technology, and publishing medium" (O’Neill, 2015, pp. 67-68). Thus, to learn these complementary concepts, students should be making decisions about message and medium when writing and producing texts.

It seems obvious that students should be both consumers and producers of information, but this Frame emphasizes other people's products. It notes how "experts look to the underlying processes of creation as well as the final product to critically evaluate the usefulness of the information" and how novices must "begin to recognize the significance of the creation process, leading them to increasingly sophisticated choices when matching information products with their information needs" (ACRL, 2015). By not explicitly calling out the students' processes for information creation, the Frame misses an opportunity to do what 
the writing studies concepts suggest. That is, to help students understand the process of information creation, they must be engaged in assignments that position them first as consumers of information - those who must understand that these kinds of decisions were deliberately made by the original authors-and second as producers of information-those who determine what kind of information to create. The understanding that students develop when producing texts, then, will deepen their evaluation and use of the information that they consume because they will have a deeper understanding of the decisions that the author made when producing that text and how it affects the message and their interpretation of that message.

The information creation as process Frame is significant because "[n]ovice learners begin to recognize the significance of the creation process, leading them to increasingly sophisticated choices when matching information products with their information needs" (ACRL, 2015). As Bazerman suggested, students need to recognize their writing and researching assignments as opportunities to communicate with a particular audience, which might, in turn, help them see how scholarly "impulses to act communicatively emerge as doable actions in the situation, in forms recognizable to others..." (Bazerman, p. 35). If scholarly writing is about the process of creating information-about making meaning-then students need to be focused on assessing the fit between their own products' creation processes and the information need they hope to fill.

Information Has Value

The Framework defines the value of information by focusing on two interrelated aspects of information. First, information plays a role in academic and public life as "a commodity, as a means of education, as a means to influence, and as a means of negotiating and understanding the world" (ARCL, 2015). Students surrounded by an information-saturated, social media driven ecosystem are wading through various kinds of information on a daily basis, and this concept is aimed at helping them understand that various kinds of information may be linked to what they are expected to learn in a classroom, while others are connected with their out-of-school experiences. This Frame also focuses on our role in helping students become experts who "understand that the individual is responsible for making deliberate and informed choices about when to comply with and when to contest current legal and socioeconomic practices concerning the value of information" (ACRL, 2015). This Frame, in turn, speaks directly to the writing studies concept that asks students to accept responsibility for how they use words and concepts. The threshold concept 
Writing Involves Making Ethical Choices (1.8) positions students as writers who should be making deliberate choices about how to contribute back to conversations. This means thinking about their source use, but as Duffy (2015) argued, the concept is bigger than citation practices. All " $[\mathrm{w}]$ riting involves ethical choices because every time we write for another person, we propose a relationship with other human beings, our readers" (p. 31). As writers enter conversations-develop authoritative voices and weigh the value of information - they must answer a series of questions: "What kind of writer do I wish to be? What are my obligations to readers? What effects will my words have upon others, upon my community?" (p. 31). These questions foreground the reality that "writing involves ethical choices" by making it clear that writing is, again, about communicating with a particular audience, which means that writing and authority are about "a relationship between writer and readers, one that necessarily involves human values and virtues" (p. 31). It is this relationship of which students must be aware in order to evaluate critically the information that they consume.

Searching as Strategic Exploration

The Framework defines the threshold concept of Searching as Strategic Exploration as a process in which searchers seek and find information via "inquiry, discovery, and serendipity" in a manner that is both contextual and complex and simultaneously affects, and is affected by, their "cognitive, affective, and social dimensions" (ACRL, 2015). The connection between Searching as Strategic Exploration and threshold concepts in writing studies is situated in analogous processes more than overlapping ideas because searching for information is a nonlinear and iterative process. It is a process in which a searcher seeks answers to a question, but is unclear of the path to those answers. Searching requires "mental flexibility," and searching requires the student to "pursue alternate avenues," explore the unknown, and let the path guide the quest (ACRL, 2015). This process of following a seemingly blurry path, often with unclear cues or direction, is articulated in writing studies in Writing Speaks to Situations through Recognizable Forms (2.0) and Writing is Performative (2.5). The first concept discusses how writers have few "here-and-now clues about what the [writing] situation is" and how to respond (Bazerman, 2015, p. 35), which means that they must experiment, or engage in writing as a performance. That is, students allow the process of writing itself to "give rise to new ideas [and] new insights" into the topic (Lunsford, 2015, p. 44). This constant reevaluation of their processes means students must apply previously acquired insights-letting them inform next steps, a meta-awareness 
that also appears in Assessment is an Essential Component of Learning to Write (4.5), in which O’Neill (2015) explicitly discussed how writers evaluate their own processes and approaches to a task.

Just as writers constantly assess their processes and allow ideas to spark new ones, information seekers engage in exploration as they constantly evaluate the information that they find and let it lead them to new or unexpected avenues. Too often students are overwhelmed with the vastness of information available when they begin to search the information ecosystem. Too many times, they become lost or paralyzed as they attempt to navigate into the unknown without real context or a heuristic strategy. To cope, they skim the surface and settle for a source that meets a superficial, minimum requirement. If programs leverage the shared idea of process, then instructors can help students develop heuristics for searching for information. By focusing information literacy and writing instruction first on the threshold concept of Scholarship as Conversation, and letting that concept drive the research process, students will have a better understanding of the conversation they are interested in engaging in. Because they will have an expectation that they should be contributing to that conversation, students will enter the information ecosystem searching for existing voices in the conversation to talk with and through, rather than searching for information to report.

\section{Conclusion}

There are writing studies concepts that extended beyond the Frames-concepts that may be useful in shaping the shared pedagogical philosophy of program integrations. For example, the Framework emphasizes lifelong learning as an outcome of its concepts, noting "dynamism, flexibility, individual growth, and community learning" across students' academic careers and in convergence with "other academic and social learning goals" (ACRL, 2015). Writing studies scholars are also interested in the growth of students, explained, for example, in the idea that learning to write requires practice, time, and effort (4.3). In the entry for this concept (4.3), Yancey (2015) suggested that "in the practice of writing, we develop writing capacities, among them the ability to adjust and adapt to different contexts, purposes, and audiences" (p. 64). The shared objective of helping students adjust and adapt their research and writing practices based on new situations and goals is something librarians and instructors can agree on. In first-year writing courses, the objective is for students to gain an understanding that (research-based) writing is situated. 
This particular concept, as Yancey (2015) argues, "locates writing specifically as a practice situated within communities, which suggests how complex writing is and how, as an activity, it spans a lifetime" (p. 65). Thus, a shared goal for program integrations-centered on the shared threshold concepts of information literacy and writing studies-should be for students to internalize practices that will result in long-range transfer and application across campuses and throughout a lifetime, a process that begins in vertical, undergraduate curricula. As undergraduates, they should be engaged in a vertical curriculum that reinforces and integrates increasingly complex understandings of both information literacy and writing.

However, "[ $t]$ his thinking represents a fundamental shift in how many writing scholars now see literacy education, from a view that is individualistic and focused on the acquisition of discrete, universal skills to one that is situated and focused on social involvement and consequences" (Scott, 2015, p. 48). Our fields' shared threshold concepts speak directly to Scott's claim and the larger goal of our project: to push disciplinary conversations away from skills and drills and to focus, instead, on core concepts. This is why we call on instructorsin the library and in the classroom-to see students as emerging experts within the higher education community. For students to engage with threshold concepts in meaningful ways, instructors must first consider the ways in which "the difficulties people have with writing are ...due to ...whether they can see themselves as participants in a particular community" (Roozen, 2015, p. 51). Students who are alienated from the learning process-those who see information literacy and writing as skills to be mastered in a single course or session-will never see themselves as contributors to conversations. Thus, the use of threshold concepts across fields "highlights the demand for structuring the curriculum in ways that allow learners to develop a sense of what it means to become a member of an academic discipline and creating models of assessment that address learners' identity work" (Roozen, 2015, p. 51). The identity work embedded in understanding and engaging with the threshold concepts of information literacy and writing studies provides a new purpose for disciplinary programs and how they can best assess students' learning not through products but through experiences. 


\section{References}

Adler-Kassner, L., \& Wardle, E. (Eds.). (2015). Naming what we know: Threshold concepts of writing studies. Boulder, CO: Utah State University Press.

Association of College and Research Libraries. (2015). Framework for information literacy for higher education. Retrieved from http://www.ala.org/acrl/standards/ilframework.

Bazerman, C. (2015). Writing expresses and shares meaning to be reconstructed by the reader. In Adler-Kassner, L., \& Wardle, E. (Eds.), Naming what we know: Threshold concepts of writing studies (pp. 21-23). Boulder, CO: Utah State University Press.

Bazerman, C. (2015). Writing speaks to situations through recognizable forms. In AdlerKassner, L., \& Wardle, E. (Eds.), Naming what we know: Threshold concepts of writing studies (pp. 35-37). Boulder, CO: Utah State University Press.

Dryer, D. (2015). Words get their meanings from other words. In Adler-Kassner, L., \& Wardle, E. (Eds.), Naming what we know: Threshold concepts of writing studies (pp. 23-25). Boulder, CO: Utah State University Press.

Duffy, J. (2015). Writing involves making ethical choices. In Adler-Kassner, L., \& Wardle, E. (Eds.), Naming what we know: Threshold concepts of writing studies (pp. 31-32). Boulder, CO: Utah State University Press.

Estrem, H. (2015). Writing is a knowledge-making activity. In Adler-Kassner, L., \& Wardle, E. (Eds.), Naming what we know: Threshold concepts of writing studies (pp. 19-20). Boulder, CO: Utah State University Press.

Hart-Davidson, B. (2015). Genres are enacted by writers and readers. In Adler-Kassner, L., \& Wardle, E. (Eds.), Naming what we know: Threshold concepts of writing studies (pp. 39-40). Boulder, CO: Utah State University Press.

Jacobson, T. E., \& Gibson, C. (2015). First thoughts on implementing the Framework for Information Literacy, Communications in Information Literacy, 9(2), 102-110.

Lerner, N. (2015). Writing is a way of enacting disciplinarity. In Adler-Kassner, L., \& Wardle, E. (Eds.), Naming what we know: Threshold concepts of writing studies (pp. 40-41). Boulder, CO: Utah State University Press. 
Lunsford, A. (2015). Writing addresses, invokes, and/or creates audiences. In Adler-

Kassner, L., \& Wardle, E. (Eds.), Naming what we know: Threshold concepts of writing studies (pp. 20-21). Boulder, CO: Utah State University Press.

Lunsford, A. (2015). Writing is performative. In Adler-Kassner, L., \& Wardle, E. (Eds.), Naming what we know: Threshold concepts of writing studies (pp. 43-44). Boulder, CO: Utah State University Press.

Meyer, J. and Land, R. (2003). Threshold concepts and troublesome knowledge: Linkages to ways of thinking and practising within the disciplines. Enhancing Teaching-Learning Environments in Undergraduate Courses Project, Occasional Report 4, 1-12.

O'Neill, P. (2015). Assessment is an essential component of learning to write. In AdlerKassner, L., \& Wardle, E. (Eds.), Naming what we know: Threshold concepts of writing studies (pp. 67-68). Boulder, CO: Utah State University Press.

Pagowsky, N. (2015). A pedagogy of inquiry. Communications in Information Literacy, 9(2), $136-144$.

Reid, G. (2014). Updating the FYC-library partnership: Recent work on information literacy and writing classrooms. WPA-CompPile Research Bibliographies, 25, 1-15.

Roozen, K. (2015). Writing is a social and rhetorical activity. In Adler-Kassner, L., \& Wardle, E. (Eds.), Naming what we know: Threshold concepts of writing studies (pp. 17-18). Boulder, CO: Utah State University Press.

Roozen, K. (2015). Texts get their meaning from other texts. In Adler-Kassner, L., \& Wardle, E. (Eds.), Naming what we know: Threshold concepts of writing studies (pp. 44-47). Boulder, CO: Utah State University Press.

Roozen, K. (2015). Writing is linked to identity. In Adler-Kassner, L., \& Wardle, E. (Eds.), Naming what we know: Threshold concepts of writing studies (pp. 50-52). Boulder, CO: Utah State University Press.

Seeber, K. P. (2015). This is really happening: Criticality in discussions of context in ACRL's Framework for Information Literacy. Communications in Information Literacy, 9(2), 157-163. 
Scott, T. (2015). Writing enacts and creates identities and ideologies. In Adler-Kassner, L., \& Wardle, E. (Eds.), Naming what we know: Threshold concepts of writing studies (pp. 48-50). Boulder, CO: Utah State University Press.

Warwick, C., Rimmer, J., Blandford, A., Gow, J., \& Buchanan, G. (2009). Cognitive economy and satisficing in information seeking: A longitudinal study of undergraduate information behavior. Journal of the Association for Information Science and Technology, $60(12), 2402-2415$.

Yancey, K. B. (2015). Learning to write effectively requires different kinds of practice, time, and effort. In Adler-Kassner, L., \& Wardle, E. (Eds.), Naming what we know: Threshold concepts of writing studies (pp. 64-65). Boulder, CO: Utah State University Press. 